\title{
Recurrent pulmonary embolism in a patient after COVID-19 treated with percutaneous and surgical approach
}

\author{
Aneta Kosiorek, Michał Kosowski, Krzysztof Reczuch, Robert Zymliński, Wiktor Kuliczkowski
}

Institute of Heart Diseases, Wroclaw Medical University, Wrocław, Poland

\author{
Correspondence to: \\ Aneta Kosiorek, MD, \\ Institute of Heart Diseases, \\ Wroclaw Medical University, \\ Borowska 213, 50-556 \\ Wrocław, Poland \\ phone: +48717331112, \\ e-mail: \\ anetakosiorek7@gmail.com \\ Copyright by the Author(s), \\ 2021 \\ Kardiol Pol. 2021: \\ 79 (9): 1042-1043; \\ DOI: 10.33963/KP.a2021.0056 \\ Received: \\ April 11, 2021 \\ Revision accepted: \\ July 5, 2021 \\ Published online: \\ July 6, 2021
}

Evidence shows an increased prevalence of venous thromboembolism (VTE) after coronavirus disease 2019 (COVID-19) [1]. Pulmonary embolism (PE) with acute pressure overload may lead to death. An early diagnosis and therapy are crucial [2].

Catheter-directed therapy (CDT) is a promising alternative to the systemic thrombolysis (ST) pathway (class C/Ila recommendation by the European Society of Cardiology guidelines), but still needs research $[3,4]$.

A 48-year-old man with a history of arterial hypertension and COVID-19 infection was admitted due to dyspnea and syncopal episodes. He had no history of deep vein thrombosis (DVT), but one day prior to admission he was driving a long distance. Laboratory tests revealed elevated concentrations of $\mathrm{D}$-dimer, cardiac troponin I (cTnl), and N-terminal B-type natriuretic peptide (NT-proBNP). Computed tomography (CT) angiography revealed a massive PE. Echocardiography showed right ventricular (RV) enlargement, shortening of pulmonary acceleration time, flattening of the interventricular septum, and McConnell's sign. Ultrasonography confirmed right popliteal vein thrombosis. Initial treatment with low- molecular-weight heparin (LMWH) was administered. However, 24 hours later, due to symptom worsening, progressing RV failure, and increasing cTnl and NT-proBNP levels, still without cardiogenic shock, the decision to start CDT (as preferred over ST) was made by the multidisciplinary pulmonary embolism response team (PERT). The PERT in our center includes interventional cardiologists, cardiac surgeons, cardiac intensive care cardiologists, and anesthesiologists. CTD was a unanimous decision. The procedure was performed under local anesthesia, via the left femoral vein access. Several passages with the Indigo Aspiration System (Penumbra Inc., Alameda, CA, USA) were done. The system utilizes an aspiration catheter connected to the engine generating negative pressure, and a retractable separator device to clear the thrombus from the catheter tip. Five thousand international units of unfractionated heparin were administered, activated clotting time was above 250 seconds. CDT resulted in a partial thrombus removal but was complicated by wire perforation of a subsegmental branch of the left PA, resulting in hemoptysis. Protamine sulfate was administered and no bleeding site was detected by angiography. After the procedure, LMWH was initially reduced but reintroduced at a full therapeutic dose over the next 24 hours since no signs of active bleeding occurred. The patient's condition and RV function were improving. However, four days later, the patient developed symptoms of cardiogenic shock with tachycardia, hypotension, and hypoxemia, with a need for inotropic and vasopressor support, and echocardiographic signs of PE recurrence. The PERT decided on surgical embolectomy and subsequently inferior vena cava (IVC) filter implantation and excluded ST due to bleeding risk. The periprocedural course was uncomplicated. The therapeutic dose of LMWH was maintained. Laboratory, genetic, and imaging testing ruled out cancer, inherited thrombophilia, antiphospholipid syndrome, autoimmune diseases, but confirmed methylenetetrahydrofolate reductase gene mutation $(677 C>T)$, which in addition to COVID-19 might provoke DVT. Echocardiography showed improved RV function. The six-month follow-up was free of VTE events.

In our opinion, the PERT-guided approach improves communication between specialists who provide complex care and facilitates difficult decisions making, including risk stratification, and therefore rapid redirection of therapeutic strategies. In patients with bleeding due to CDT and subsequent anticoagulation 

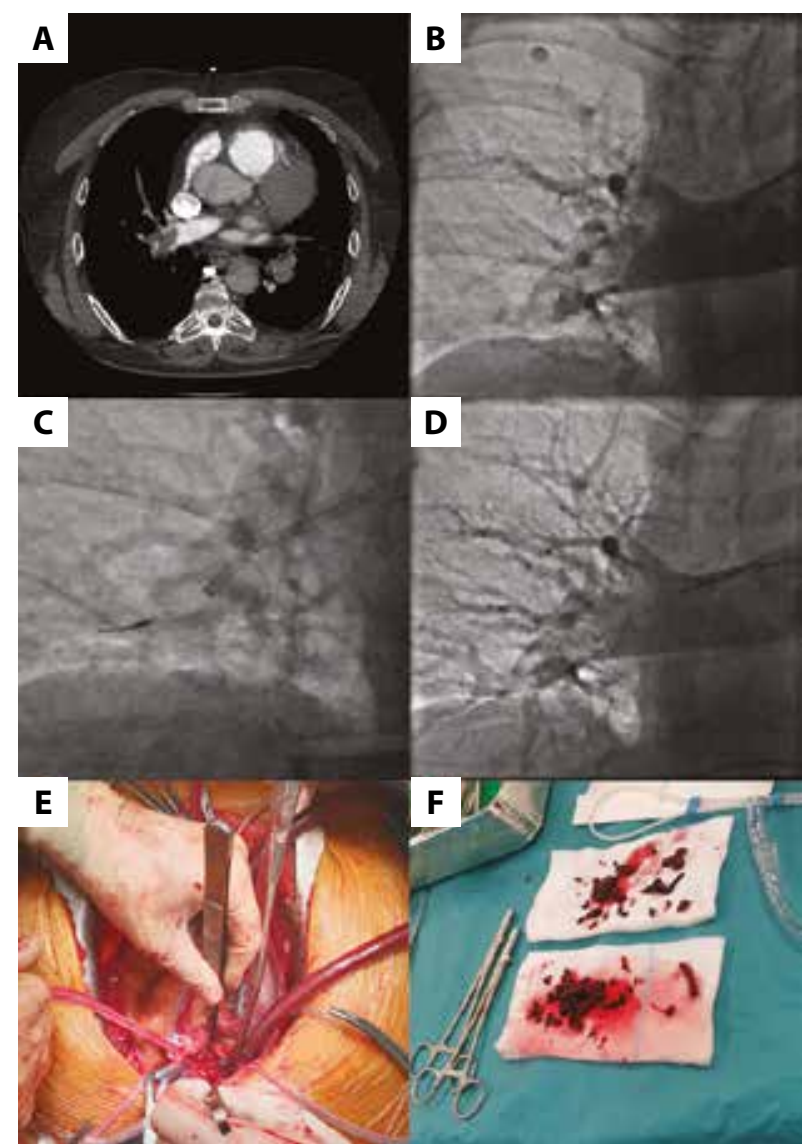

Figure 1. A. Computed tomographic pulmonary angiography. B. Pulmonary angiography prior to thrombectomy. C. Pulmonary thrombectomy - Indigo Aspiration System. D. Pulmonary angiography after thrombectomy. E-F. Surgical embolectomy stopping, IVC filter implantation may be considered to avoid recurrence of $P E$.

\section{Article information}

Conflict of interest: None declared.

Open access: This article is available in open access under Creative Common Attribution-Non-Commercial-No Derivatives 4.0 International (CC BY-NC-ND 4.0) license, allowing to download articles and share them with others as long as they credit the authors and the publisher, but without permission to change them in any way or use them commercially. For commercial use, please contact the journal office at kardiologiapolska@ptkardio.pl.

How to cite: Kosiorek A, Kosowski M, Reczuch K, et al. Recurrent pulmonary embolism in patient after COVID-19 treated with percutaneous and surgical approach. Kardiol Pol. 2021; 79(9): 1042-1043, doi: 10.33963/KP.a2021.0056.

\section{REFERENCES}

1. Sakr Y, Giovini M, Leone M, et al. Pulmonary embolism in patients with coronavirus disease-2019 (COVID-19) pneumonia: a narrative review. Ann Intensive Care. 2020; 10: 124, doi: 10.1186/s13613-020-00741-0, indexed in Pubmed: 32953201.

2. Dilektasli AG, Demirdogen Cetinoglu E, Acet NA, et al. Catheter-directed therapy in acute pulmonary embolism with right ventricular dysfunction: a promising modality to provide early hemodynamic recovery. Med Sci Monit. 2016; 22: 1265-1273, doi: 10.12659/msm.897617, indexed in Pubmed: 27081754.

3. Avgerinos ED, Abou Ali A, Toma C, et al. Catheter-directed thrombolysis versus suction thrombectomy in the management of acute pulmonary embolism. J Vasc Surg Venous Lymphat Disord. 2019; 7(5): 623-628, doi: 10.1016/j.jvsv.2018.10.025, indexed in Pubmed: 30902560.

4. 2019 ESC guidelines for the diagnosis and management of acute pulmonary embolism developed in collaboration with the European Respiratory Society (ERS): the task force for the diagnosis and management of acute pulmonary embolism of the European Society of Cardiology (ESC). Eur Heart J.2019;54(3): 1901647, doi: 10.1183/13993003.01647-2019, indexed in Pubmed: 31473594. 